\title{
Leprosy in Argentine.
}

E. P. Fidanza.

\section{History.}

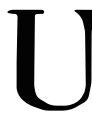

NTIL quite recently a case of leprosy was looked upon as a rarity and commented upon with surprise. It was known that a certain district of the country was inf ected but this raised no alarm as the infection was believed to be limited to that district, and no new cases were described outside. In the most important works on leprosy, when considering the geographical distribution, all the southern part of South America, including Argentine and Chile was reported free from the disease. During recent years the absence of prophylactic precautions, together with better medical knowledge of the disease, has brought to light the bitter truth of the situation, namely, an increase in the incidence of cases ; a consequence foreseen for some time past, and of which the public authorities took no heed for many years.

The origin of leprosy in the Argentine is difficult to establish. Most historians agree that the indigenous population was free from leprosy, the disease being introduced after the discovery by the colonists. It is supposed that some of the black slaves brought from Africa to Brazil were infected, and later they emigrated down the River Paraná, disseminating the disease along its borders. Even in our day this district is the one most severely attacked. Others maintain that leprosy was first introduced to the Argentine coast by a Norwegian sailing boat about 1850 . The crew, many of whom were infected with leprosy, settled in different towns along the River Paraná, e.g., Bella Vista and Reconquista, and from there spread the disease to other parts of the country. This theory can be ruled out as cases of leprosy were known to exist in the country before that time. 
Statistics.

The first figures referring to the number of cases of leprosy in the country date from 1891 when it was calculated there were about 300 . In 1906 a congress for the purpose of discussing the disease met in Buenos Aires and from data supplied by the representatives from the different provinces a total of 700 living cases was obtained. It is only after this date that Penna and authorities like Sommer and Aberastury called attention to the seriousness of the problem and the invasive tendency of the disease. Later Baliña and Puente in Buenos Aires and myself in Rosario (Santa Fé) have insisted in publications and lectures on the urgent necessity for definite, complete prophylactic measures.

In 1928, the National Public Health Department sent out a questionnaire to more than 5,000 doctors, referring to the incidence of leprosy. About half answered, and 1,560 cases were reported ; it is calculated that if all had replied the figure would have been more like 3,000. The majority of leprologists agree that the total number of persons affected can be approximately determined by multiplying the reported cases by two. In that case the number of cases in the country is between 6,000 and $7,000, i . e$., the total population being over eleven millions, there are five cases per 10,000 inhabitants.

In 1929, the National Public Health Department sent out commissions to several provinces to establish a census; 1,800 cases were reported, a figure we believe far below the actual number owing to certain defects in the manner with which the census was carried out.

\section{Epidemiology.}

The country is not attacked equally in all its districts. In certain parts the disease is observed while elsewhere is almost free. The provinces most affected are those which border the River Paraná: Corrientes, Entre Rios, and Santa Fé, which make up the Littoral Argentino, together with Misiones, Chaco and Formosa, and part of the Province of Buenos Aires. This region which occupies about one-fifth of the country and contains 40 per cent. of the population, has no less than 87 per cent. of the cases of leprosy.

Why are the greater proportion of sufferers in this region? We attribute it to three factors :-

(1) In these provinces, particularly Santa Fé, Corrientes and Entre Rios, the first foci of leprosy appeared and the disease has followed its invasory tendency during more than 80 years without the slightest prophylactic measures on the part of the authorities. 
(2) This region has the dampest and hottest climate in the country which confirms the opinion of most leprologists, such as Sir Leonard Rogers, that the disease flourishes best under these climatic conditions, following the courses of the rivers.

(3) This region contains the two centres for the study of leprosy, Buenos Aires and Rosario, where the early diagnoses, which constitute a large proportion of the statistic figures, are made.

The second region, much less important, is composed of the provinces forming the centre of the country, Córdoba, San Luis, Tucuman, Salta, \&c., which give together 11 per cent. of those infected.

On the other hand, the provinces bordering on the Andes, Mendoza, San Juan, and Territory of the Andes, are practically free, only giving 2 per cent. of the total number of cases.

\section{To Sum Up.}

The geographical distribution of leprosy in the Argentine can be divided into three regions which are :-

(A) The littoral, badly infected and limited to the east by countries also severely infected by the disease, e.g., Brazil, Paraguay and Uruguay. (See map facing p. 128.)

(B) The middle region, much less infected but still with over 10 per cent.

(C) The Andine or Cordillera region which can be classified as free and which is limited on the West by Chili where leprosy is rare. (See map.)

A similar map has been published by Professor Baliña (Sem. Med. 1928, No. 47); we have modified it so as to show the greater incidence of cases in the region of great rivers.

\section{Clinical Types.}

I believe, generally speaking, the disease presents itself in a benign form and that the severe bacillary types described are due in most cases to a mistaken diagnosis in the early stage and consequent bad treatment or neglect. Under these circumstances when the patient returns to a centre where the disease is well known, his illness, which started as a simple lesion, has now become generalised and deformative and, therefore, is considered serious. For many years amongst my students in the Faculty of Medicine I have insisted on the importance of early diagnosis and have thus contributed to the fact that to-day a much larger number of cases are 
recognised at the beginning of the disease, which permits of its arrest and improvement. Our experience shows us that the forms usually occurring amongst the out-patients attending the skin department are the $\mathrm{C}_{1} \mathrm{~N}_{1}$ in accordance with the latest classification of Manila ; and we insist that the day the disease is better known in the country, a different view of its gravity will be taken. Of 150 cases which attended at the Hospital Carrasco of Rosario more than 110 pertain to type $\mathrm{C}_{1} \mathrm{~N}_{1}$. The second place is occupied by the tubercular form $C_{2}$, the purely nervous forms $N_{1} N_{2}$ being much less frequent. These proportions I consider interesting enough to note.

\section{Prophylaxis.}

We must admit that till to-day extremely little has been done for the cases of leprosy. Last century anti-leprosy prophylaxis was nil, though as a historical fact it can be mentioned that a colony for sufferers from the disease was founded in Colastiné (Province of Santa Fé), but owing to a revolution in 1878 , the patients escaped, probably spreading the disease throughout the province and the establishment was closed. It was only at the beginning of this century and as a result of the Leprosy Conference organised by the National Department of Public Health in 1906, that the adoption of prophylactic measures on the part of the public authorities was voted and a law formulated which unfortunately did not materialise. However, the seed was sown, and although the instigators of the prophylaxis campaign, whose names are worthy to be venerated, Penna, Sommer and Aberastury, have not been able to realise the work they visualised, their pupils, amongst whom are Baliña, Puente, myself and many others, recognise their efforts and continue their work.

In 1923, the Government commissioned Professor Aberastury to form a law on National Prophylaxis against Leprosy which in 1926 became Law No. 11,359. In honour of the scientist we call this Aberastury's Law. Unfortunately the application of the law has not been possible so far, owing to the indifference of the public authorities.

During these last years, Dr. Puente, director of the Leprosy Section in the National Department of Public Health, has effected by order of the Government, the acquisition of large territories in Corrientes, Entre Rios, Córdoba, Salta, \&c., for the creation of Leprosy Colonies, one of which is nearly ready on the island of Cerrito (Corrientes).

To-day in the Argentine Republic we only have two 
places for the exclusive treatment of cases of leprosy, which are :-

\section{(1) The Leprosy Block of the Hospital Muniz (Buenos Aires).}

This was created at the instigation of Prof essor Penna in 1900, and occupies a section of the Hospital Muniz, which is exclusively for infectious and contagious diseases.

Although large the block is too small to accommodate the large number of cases who flock to it from the interior of the country, and which until three years ago was their only asylum.

At present in the block are housed 200 patients, the tubercular and mutilated forms predominating, many of whom no longer receive treatment.

\section{(2) The Leprosy Block of the Hospital Carrasco (Rosario).}

This was created at my instigation, together with the help of Doctors Fernandez and Schujman in 1921, and occupies part of the Hospital Carrasco which is reserved for infectious and contagious diseases.

This department, which at its beginning had to overcome enormous difficulties owing to the fact it had no official recognition, now, in spite of the small number of available beds, constitutes the most important leprosy centre in the country, not only for the public service it renders but also because it has become a centre of study and research applied to the treatment of the disease as we shall see later. of :-

The Leprosy Section of the Hospital Carrasco consists

(1) A ward for men with 22 beds for cases type $C_{1} N_{1}$ to which the patients are only admitted for special forms of treatment which are difficult to apply as out-patients.

(2) A ward for men with 15 beds devoted to the most contagious cases of types $\mathrm{C}_{2} \mathrm{~N}_{2}$ and $\mathrm{C}_{3} \mathrm{~N}_{3}$.

(3) A small ward with 13 beds for women, thus giving a total of 50 in-patients.

(4) A special out-patient consulting room which is used exclusively for the treatment of leprosy, where about 110 patients are treated who receive two or three weekly in jections. Most of these cases are only slightly contagious.

(5) A section for the examination of contacts of which we submitted a special file for the consideration of the Committee on Leprosy of the League of Nations. Actually there are more than 350 files with information of examinations effected every three months, which without doubt will 
provide important epidemiological data to be the subject of a special publication.

(6) A consulting room for diseases of the skin at the entrance of the hospital which has given excellent results as it functions in an infected district and has permitted the discovery of early cases.

\section{Treatment.}

Generally speaking, we can say in our country the derivatives of chaulmoogra oil are exclusively used, preferably the ethyl esters of Taraktogenos kurzii and Hydnocarpus wightiana. We have tried many medicaments in the department but our best results have been obtained using esters of the Chaulmestrol and Alepol type with potassium iodide. We agree (with Dr. Cochrane) that potassium iodide can be given in small doses to the incipient varieties without producing harmful general reactions. Using these drugs together during three years, in more than 100 cases we have obtained highly satisfactory results which we have already published. Shortly we are publishing a more complete work on the subject.

On a lesser scale we have used Ginoilo iodade and coloidal chaulmoogra, both Argentine products prepared for us by Dr. Oreste Calcagno.

We have been studying the action of Leprosan or Catosan sent us by Bayer and Co., and have obtained some interesting results which we will describe later. For local treatment we use carbon-dioxide snow and 50 per cent. trichloracetic acid with good results.

But above all, I wish to draw attention to the importance of keeping the general health of the patient in good condition without which measure all specific treatment fails. At the same time it is necessary to raise the morale of the patients by providing them with mental comfort and distractions. By encouraging the patients they become optimistic and constant in their attendance for the continuation of the treatment, so much so that our patients never stop visiting us and at times more of ten than we demanded, and we see in their expressions of gratitude that they recognise us as their helpers and not their persecutors.

The humanitarian sentiment of the rest of the people seems to be waking from its lethargy and several societies have been started by ladies anxious to lighten the burden of these miserable sufferers.

We welcome all help, both moral and material which will aid us in a few years to rid the country of this disease. 